\title{
ARTICULAÇÃO DE COMPETÊNCIAS NO PODER MUNICIPAL: UM ESTUDO SOBRE A SUA RECENTE REFORMA EM PORTUGAL
}

\section{The distribution of responsibilities in the city administration: a research about its recent reform in Portugal}

\author{
João Ricardo Catarino ${ }^{1}$ \\ Miguel Matias Reis Silva ${ }^{2}$ \\ José Sérgio da Silva Cristóvam ${ }^{3}$
}

1 Doutor em Ciências Sociais na Especialidade de Administração Pública pela Universidade Técnica de Lisboa (UTL) (2008). Mestre em Ciência Política pela Universidade Técnica de Lisboa (UTL) (1999). Licenciado em Direito pela Universidade de Lisboa (ULisboa) (1985). Professor do Instituto Superior de Ciências Sociais e Políticas (ISCSP) da Universidade de Lisboa (ULisboa). Investigador integrado no Centro de Administração e Políticas Públicas (CAPP), ISCSP-ULisboa, reconhecido pela FCT. Membro do Colégio de Especialidade da OTOC - Ordem dos Técnicos Oficiais de Contas. Árbitro no CAAD - Centro de Arbitragem Administrativa. É membro da Associação Fiscal Portuguesa, do Conselho Consultivo da Revista de Finanças Públicas e de Direito Fiscal (Portugal), da Comissão de Redação da Revista Fiscalidade (Portugal) e da Revista de Direito Tributário (Brasil), e da Revista de Direito Econômico e Financeiro (Brasil). É autor de vários estudos sobre Fiscalidade e Finanças Públicas. E-mail: jcatarino@iscsp.ulisboa.pt

2 Licenciado em Ciência Política (2003) pelo Instituto Superior de Ciências Sociais e Política (ISCSP), com Especialização em Gestão da Decisão Política. Frequentou a pós-graduação em Gestão e Administração Autárquica entre 2004 e 2005; Concluiu o Mestrado em Administração Pública (MPA), especialização em Administração Autárquica em 2014. Exerce a sua atividade profissional no Município da Lourinhã, onde desempenha funções de direção na área da Modernização Administrativa. Investigador Associado no CAPP - Centro de Administração e Políticas Públicas (CAPP), ISCSP-ULisboa. E-mail: miguel.silva@cm-lourinha.pt

3 Doutor em Direito Administrativo pela UFSC (2014), com estágio de Doutoramento Sanduíche junto ao Instituto Superior de Ciências Sociais e Políticas (ISCSP) da Universidade Técnica de Lisboa (Portugal). Mestre em Direito Constitucional pela UFSC (2005). Especialista em Direito Administrativo pelo CESUSC (2003). Professor de Direito Administrativo nos Cursos de Graduação e Pós-Graduação em Direito do CESUSC. Professor de Direito Administrativo na ESMESC, na ESA -OAB/SC e na ENA/Brasil, em convênio com a École Nationale d'Administration (I'ENA/França), bem como em Cursos de Pós-Graduação em Direito da UNIDAVI, 
Resumo: Os poderes dos órgãos do Poder Municipal nem sempre se articulam adequadamente. As reformas da Administração Municipal realizadas em todo o mundo têm como objetivo essa melhoria. A mais recente reforma, ocorrida em Portugal em 2013, visou igualmente essa finalidade e inspirou-se no Documento Verde da Reforma da Administração Local, lançado em 2011 pelo XIX Governo Constitucional. Os objetivos definidos são os de melhorar a eficiência e a eficácia da gestão pública e definir um novo paradigma da gestão local, por meio de uma melhor organização do território, da melhoria da gestão e do financiamento e do reforço da democracia local. Este ensaio visa averiguar o impacto que esta reforma teve nas competências dos órgãos autárquicos mais importantes: as Assembleias Municipais, as Câmaras Municipais, os Presidentes de Câmara e as Juntas de Freguesia (subunidades municipais). A escolha desses órgãos deve-se
Abstract: It is not easy to properly coordinate the power of local government bodies. The local government reforms taking place around the world aim to improve this coordenation. The latest reform of the Portuguese local government (in 2012) had the same aim and was based on the Green Paper for Local Government Reform, issued in 2011 by the XIX Constitutional Government. The defined objectives are to improve the efficiency and effectiveness of public administration and set a new paradigm of local management, by improving the organization of the territory, improving management and financing, and strengthening local democracy. This paper aims to investigate the impact this reform had on the legal competencies of the major municipal bodies: municipal assemblies, municipal councils, mayors and parish councils. These bodies were chosen because of the irdeliberative and executive power at municipal level.

UNOESC, UNISUL, UnC, Estácio de Sá e diversas outras instituições. Membro fundador e Presidente do Instituto Catarinense de Direito Público (ICDP). Membro fundador do Instituto de Direito Administrativo de Santa Catarina (IDASC) e da Academia Catarinense de Direito Eleitoral (ACADE). Membro efetivo do Instituto dos Advogados de Santa Catarina (IASC). Conselheiro Estadual da OAB/ SC (triênio 2013-2015). Vice-Diretor Geral da ESA-OAB/SC (triênio 2013-2015). Presidente do Comitê de Mobilização para a Reforma Política (OAB/SC). Membro da Comissão de Direito Constitucional e da Comissão da Moralidade Pública da OAB/SC (triênio 2013-2015). Assessor Jurídico do Sindicato dos Trabalhadores na Rede Estadual de Ensino de Santa Catarina (SINTE/SC). Advogado militante na seara do Direito Público. E-mail: jscristovam@gmail.com 
ao fato de serem os que detêm os poderes deliberativo e executivo no nível municipal.

Palavras-chave: Administração local em Portugal. Reforma. Competências. Autarquias locais.
Keywords: Local administration in Portugal. Reform.

Competencies. Local authorities.

\section{INTRODUÇÃO}

A importância do Poder Local não é apenas histórica, mas constitui sim uma manifestação importante do poder democrático e uma destacada forma de gerir o interesse público em Portugal. Com efeito, as competências dos órgãos do poder local português têm-se expandido à medida que novas competências vêm sendo transferidas, como é o caso da educação pré-escolar, habitação social, segurança pública, impostos e as questões ambientais, a partir da reforma legislativa portuguesa de 2013 (COSTA, 2014). O fenômeno é geral, havendo um aprofundamento das competências do poder local, assim como dos recursos que lhe são afetos (OCDE em vários estudos).

Isso tem sido posto em prática por meio de reformas ao quadro legal, como é o caso da reforma territorial das freguesias portuguesas (Lei n²2/2012, de 30.05.2012), do Regime Jurídico da Reorganização Administrativa Territorial Autárquica, das alterações do Estatuto do pessoal dirigente dos serviços e organismos da administração central, regional e local do estado (Lei $n^{\circ}$ 49/2012, de 29.8), do Regime Jurídico das Autarquias locais, das entidades intermunicipais, da transferência de competências do Estado para as autarquias locais e para as entidades intermunicipais e do regime jurídico do associativismo autárquico (Lei n. 75/2013, de 12.09.2013).

$O$ debate sobre essas reformas no sistema da Administração Local portuguesa interessa em especial ao Brasil, não somente pela estreita relação histórica entre nossos países, mas 
também pela possibilidade de contraponto e análise crítica do sistema de distribuição das competências no âmbito municipal brasileiro, a partir do estudo do Direito comparado.

Partindo de uma análise teórico-normativa das estruturas de Poder Local em Portugal, o presente ensaio apresenta uma análise detalhada dos possíveis impactos das referidas reformas na estrutura da Administração Local lusitana, a partir, também, da ótica dos gestores e administradores públicos envolvidos com a atividade administrativa local, por meio de estudo/pesquisa de campo (questionários, entrevistas e gráficos ilustrativos), que representa uma relevante instrumento de análise sobre as consequências práticas daquelas reformas administrativas.

Em verdade, as alterações são majoritariamente estruturais, embora variem em cada país. Todavia, todos buscam alcançar uma melhor reorganização territorial, a racionalização do poder local e a distribuição de responsabilidades e competências. Nesse sentido, a evolução verificada especificamente em Portugal, país objeto desta pesquisa, pode servir de inspiração para outras reformas do poder local.

\section{A ADMINISTRAÇÃO LOCAL: MODELOS DE GOVERNO, PRINCÍPIOS DO PODER LOCAL E ORGANIZAÇÃO ADMINISTRATIVA}

A Constituição da República Portuguesa de 1976 (CRP/1976) estabelece em seu art. 236 as três categorias de autarquias locais: Freguesias, Municípios e Regiões Administrativas. Os Municípios portugueses são estruturas do sistema político-administrativo português desde a Idade Média (AMARAL, 1991, 2014).

Existem sete aspectos que tornam o Município a autarquia local com maior impacto na sociedade e com maior relevância administrativa: Tem paralelo internacional; foi a primeira a surgir; tem uma influência política e uma responsabilidade econômica elevada, nomeadamente com relação ao investi- 
mento e manutenção de infraestruturas públicas; a importância em nível administrativo da estrutura dos Municípios; o relevante peso financeiro nas finanças públicas locais; a relevância jurídica, pois o Direito Administrativo teve a sua gênese no Direito Municipal; os Municípios estão no final da cadeia de desenvolvimento das políticas públicas, tornando mais visível a sua atuação (AMARAL, 1991, 2014).

O modelo de Governo local português é um "modelo de patrocinador" (BILHIM, 2004, p. 26-27), característico dos países do sul da Europa, onde os eleitos locais gerem os seus sistemas locais de forma a patrocinar o máximo de bem-estar possível às suas populações. Todavia, ele tem aspetos característicos de outros modelos, pois as autarquias portuguesas possuem características próximas do modelo anglo-saxónico, onde os Governos locais são agentes de promoção do crescimento da economia local (BILHIM, 2004, p. 26-27).

O modelo de "patrocínio específico" (RUIVO, 2000) é o que mais se destaca, pois o eleito local centraliza em si as grandes virtudes do seu Município, destacando o seu papel de dinamizador local naquilo que são as suas responsabilidades junto aos eleitores, nomeadamente na prestação dos serviços públicos. O eleito local move-se dentro do seu sistema de contatos, nos diferentes níveis da administração pública, desenvolvendo assim um papel de mediador e de promotor dos interesses locais, promovendo o território do qual é gestor (GOLDSMITH apud RUIVO, 2000). MOZZICAFREDO considera que o poder municipal independente transformou-se em um verdadeiro presidencialismo municipal, que surge na esfera da política local, no qual é desenvolvida uma teia de relações de poder que permitem a valorização da imagem do próprio Presidente (MOZZICAFREDO et al., 1988, In: FRANCO; AMARAL, 2000, p. 89).

Em uma segunda perspetiva, o poder do eleitorado influencia as ações do decisor local e, consequentemente, o desenvolvimento local. Assim, os Municípios são uma espécie 
de dependências do próprio Estado, prestando serviços públicos às populações locais. $\mathrm{O}$ segundo modelo é caracterizado como napoleónico francês, cuja origem é a reforma administrativa imposta pela lei (BILHIM, 2004, p. 27).

O Governo local português é marcado por um culto da imagem do Presidente da Câmara, que é a figura principal do Governo local. Apesar de o sistema político não ser presidencialista, essa imagem é o resultado do cunho pessoal que o Presidente da Câmara dá a toda "obra" realizada, mas também do papel de mediador que este tem junto dos interesses corporativos locais e nacionais, quer sejam institucionais ou partidários (MOZZICAFREDO et al., 1988, In: FRANCO; AMARAL, 2000, p. 88-89).

Cidadãos mais exigentes com os serviços públicos (cidadiania ativa e participativa) obrigam os eleitos locais a adaptarem as suas estruturas administrativas às reais necessidades da população, tendo também em vista a manutenção do poder. Nesse sentido, CROZIER (apud BILHIM, 2004) refere que há uma cumplicidade política e administrativa, na qual o elo mais fraco é o sistema administrativo, pois para além de ter de dar resposta ao círculo legislativo (cumprimento de leis), tem de acatar as orientações dos diferentes estratos internos da organização.

\section{OS PRINCÍPIOS CONSTITUCIONAIS RELATIVOS ÀS AUTARQUIAS LOCAIS}

A CRP/1976 refere, no seu art. 6º que o Estado Português é unitário e respeita o regime da autonomia insular, bem como os princípios da subsidiariedade e autonomia das autarquias locais, e da descentralização democrática da administração pública. Assim, num único artigo, a Constituição portuguesa faz referência a quatro características das autarquias: Autonomia do Poder Local; Estado unitário; subsidiariedade; e descentralização administrativa. 
A autonomia dos municípios é um dos princípios basilares da organização do Estado português, associada à distribuição efetiva de poderes públicos entre o Estado, as Regiões Autónomas e as Autarquias Locais, garantindo, desse modo, que o Estado-Administração não tem em si o poder absoluto (CONDESSO, 2012, p. 33).

Da autonomia do Poder Local sobressaem diferentes tipos de autonomia: Autonomia administrativa; autonomia normativa e organizacional; autonomia financeira; autonomia patrimonial; autonomia na fixação de taxas e tarifas; autonomia e liberdade de associação e cooperação.

O princípio constitucional da autonomia local está associado à capacidade conferida às autarquias para prosseguirem livremente e sob sua responsabilidade e por meio de órgãos próprios, a concretização de atribuições legalmente conferidas, visando a prossecução dos interesses que dizem respeito às populações residentes (CONDESSO, 2012, p. 39).

Por outro lado, o princípio da subsidiariedade é uma das características de um Estado democrático, mas também de um sistema político-administrativo desenvolvido. Segundo o artigo $4^{\circ}$ da Carta Europeia de Autonomia Local, o exercício das responsabilidades públicas deve estar afeto às autoridades mais próximas dos cidadãos. A atribuição de uma responsabilidade a outra autoridade deve ter em conta a amplitude e a natureza da tarefa e as exigências de eficácia e economicidade.

Dessa forma, o que pode ser provido por um serviço público local não deve ser feito por um central ou o topo da hierarquia do Estado. Para ROCHA (2005, p. 213), qualquer função ou atividade deve ser desenvolvida ao mais baixo nível da escala sociopolítica, desde que seja assegurada a inocorrência de prejuízos à eficiência administrativa. Porém, o motivo não é apenas a eficiência e a eficácia da atividade, mas também a participação do cidadão na tomada da decisão local, a dignidade e o lugar da pessoa humana no sistema político (MOREIRA apud ROCHA, 2005, p. 215). 
A descentralização administrativa, consagrada no art. 237 da CRP/1976, implica uma distribuição de competências entre os diversos órgãos das autarquias locais. Essa descentralização está associada ao princípio da autonomia, pelo que uma entidade superior (o Estado) dota outra inferior (a Autarquia) com suas atribuições (CONDESSO, 2012, p. 60).

A descentralização focada nas autarquias é territorial (AMARAL, 1991), pois o Estado, no espírito do princípio da subsidiariedade, atribui competências e transfere atribuições para as autarquias locais que originariamente são suas.

A representatividade dos órgãos que compõem as autarquias locais é uma característica fundamental, já que sem estes não há Autarquia Local. Cada Autarquia é composta por diferentes órgãos representativos eletivos, em eleições autárquicas, apurados segundo o método de Hondt. Assim, a Freguesia é composta pela Assembleia de Freguesia e pela Junta de Freguesia; o Município é composto pela Assembleia Municipal e pela Câmara Municipal; a Região Administrativa é composta pela Assembleia Regional e pela Junta Regional. A Região Administrativa ainda está por implementar.

Em Portugal existem 308 Municípios, sendo que 278 se localizam no Continente, e os 30 restantes estão nas Regiões Autônomas. Segundo dados do INE (2001), a dimensão demográfica média dos Municípios portugueses é de 33.600 habitantes/Município. Para MAFRA e SILVA (2004), a estrutura municipal portuguesa é mais consistente do que a espanhola (4.800 habitantes/Município), ou a francesa (1.600 habitantes/ Município), pois um Município português agrega em média um contingente populacional expressivamente maior que os Municípios dos países mencionados.

\section{OBJETO E OBJETIVOS DO ESTUDO APRESENTADO}

Feitas essas considerações elementares sobre o sistema de Poder Local portugês, segue a partir de agora as considerações 
específicas sobre o objeto desse estudo - o Poder Local. Os objetivos fundamentais da pesquisa são três: (1) aferir se a reforma de 2013 trouxe uma melhor articulação de funções entre a Junta de Freguesia e a Câmara Municipal; (2) aferir se as competências das Assembleias Municipais, das Câmaras Municipais e do Presidente da Câmara foram reforçadas; (3) aferir se as competências de fiscalização da Assembleia Municipal foram reforçadas.

Nessa toada, são formuladas as seguintes hipóteses básicas: H 1 - A reforma melhora a articulação de funções entre a Junta de Freguesia e a Câmara Municipal; H 2 - A reforma reforçou as competências da Assembleia Municipal, da Câmara Municipal e do Presidente da Câmara; H 3 - A reforma reforça o papel das Assembleias Municipais, como órgão fiscalizador da ação da Câmara Municipal e do Presidente.

$\mathrm{O}$ âmbito da pesquisa cinge-se aos Municípios abrangidos pela Comunidade Intermunicipal do Oeste (OesteCIM). (Cf. http://www.oestecim.pt/).

A pesquisa desenvolve-se em duas partes. Na primeira, resta promovida uma análise conceitual do tema, com foco nos princípios legais e constitucionais mais diretamente aplicáveis às autarquias locais. Analisa-se o impacto do novo Regime Jurídico das Autarquias Locais e das Entidades Intermunicipais aprovado pelo XIX Governo Constitucional pela Lei n 75/2013, até mesmo a partir da coleta da opinião dos autarcas (gestores, administradores) da região Oeste. A metodologia adotada teve como base a aplicação de questionários e entrevistas. A análise dos resultados está fundada em uma base qualitativa, assente na utilização de pesquisa bibliográfica e análise documental.

O universo de estudo analisado são os autarcas em exercício de funções nos diferentes órgãos autárquicos nas autarquias que fazem parte da OesteCIM. A escolha da região deve-se ao fato de a região Oeste ocupar 2,4\% do território nacional e de a sua população representar $3,4 \%$ do total do país, apresentando uma densidade populacional elevada $(160,5 \mathrm{hab} / \mathrm{km} 2$, contra $114,8 \mathrm{hab} / \mathrm{km} 2$ no país), o que a coloca na $11^{\mathrm{a}}$ posição 
entre as 30 NUTS III'; de apresentar uma taxa de atração de 5,31\%, consideravelmente superior à taxa de atração da região de referência (Região de Polarização de Lisboa) e da própria região Centro; de ser representativa ao nível político partidário, com a presença nos órgãos autárquicos de quatro dos seis partidos representados na Assembleia da República; e por estar dentro das médias nacionais a partir de vários indicadores macroeconômicos (OesteCIM, 2008).

Foram utilizados questionários para colher as opiniões de especialistas e dos principais intervenientes no Poder Local, tendo-se auscultado, por este método, 21 dos 48 membros da Assembleia Intermunicipal desta Região. As entrevistas foram aplicadas com o objetivo de colher a opinião de Presidentes de Assembleias Municipais e Câmaras Municipais na área objeto de estudo. Nas entrevistas, considerou-se o universo de 12 Presidentes de Câmara e 12 Presidentes de Assembleia Municipal, tendo como amostra 6 entrevistas realizadas, mais precisamente a 3 Presidentes de Câmara e a 3 Presidentes de Assembleia Municipal.

Como forma de apoio à interpretação dos resultados, estudaram-se os diplomas legais em vigor e respetivas propostas de alteração com o objetivo de recolher dados fiáveis para traçar um mapa comparativodas competências dos órgãos autárquicos para suportar as conclusões.

\section{A REFORMA DA ADMINISTRAÇÃO LOCAL DE 2013}

O XIX Governo Constitucional publicou o Regime Jurídico da Reorganização Administrativa Territorial Autárquica por meio da Lei $n^{\circ} 22 / 2012$ e a Lei $n^{\circ} 75 / 2013$, que consagrou a reforma da Administração Local, alterando as competências dos órgãos autárquicos, definindo as relações entre estas e as entidades intermunicipais. A análise comparativa desenvolvida

4 NUTS são Unidades Territorias para Fins Estatísticos. Mais informação disponível em: http://www.oestecim.pt/_uploads/ProgramaTerritorialdeDesenvolvimentodoOeste.pdf 
teve como base as competências da Assembleia Municipal e da Câmara Municipal.

Esses diplomas tem por base o compromisso de Portugal para com a TROIKA (MoU, 2011), de reorganização da Administração Local, diminuindo o número de Autarquias no território português e agregando Freguesias e Municípios. Essa reforma foi das mais profundas das últimas décadas. Assim, foi muito reduzido o universo das Freguesias: de 4.259 para 3.092 (ANAFRE, 2012). A Reforma da Administração Local é um dos pilares do MoU (DOCUMENTO VERDE DA REFORMA DA ADMINISTRAÇÃO LOCAL, 2011, p. 08).

Considerando o enquadramento político, bem como a meta fixada, os principais objetivos desta reforma foram a maximização dos recursos (fazer mais com menos); o aumento da eficiência e eficácia dos serviços; o reforço do municipalismo e promoção da coesão e competitividade nacional (DVRAL Documento Verde da Reforma da Administração Local, 2011, p. 08). Para tanto, foram definidos quatro eixos (DVRAL, 2011, p. 16), sendo que para cada eixo foram estabelecidos diversos objetivos e uma metodologia própria.

No eixo do Setor Empresarial Local (SEL), o DVRAL refere a necessidade de realizar um diagnóstico que permita saber o peso deste setor na Administração autárquica. Com base nesse diagnóstico, pretendia-se adequar a sua real necessidade às autarquias. No eixo relativo à Organização do Território foram definidos dois objetivos principais: a redução do número de freguesiase o aumento de competências dos Municípios e Freguesias. No terceiro eixo (Gestão Municipal, Intermunicipal e Financiamento), foi definido um objetivo principal: diminuir o número de dirigentes municipais, por meio da definição de limites e critérios em função da dimensão populacional e financeira das estruturas locais. No quarto eixo (Democracia Local) são abordadas as áreas relacionadas com a formação e composição dos executivos, o número de eleitos locais, a representatividade das listas candidatas e as competências da Assembleia Municipal. 
Considerando as especificidades locais, a reforma da Administração Local pretendia criar um modelo de "executivo homogéneo"; aumentar as competências do Presidente da Câmara, que passa a poder escolher os seus vereadores de entre os membros da Assembleia Municipal; a redução do número de membros do executivo camarário e da Assembleia Municipal, tendo por base o número de eleitores de cada Município; o reforço de poderes de fiscalização da Assembleia Municipal; o estabelecimento de novos critérios de determinação do número máximo de dirigentes municipais, consoante as diferentes categorias definidas para os Municípios.

Nesse sentido, previa-se a alteração dos diplomas legais que regulavam as competências e o regime específico que regula o funcionamento dos órgãos municipais e das freguesias, a transferência de atribuições e competências de outras entidades para as autarquias locais.

\section{RESULTADOS SOBRE O IMPACTO DA REFORMA DO PODER LOCAL NAS COMPETÊNCIAS DOS ÓRGÃOS MUNICIPAIS}

No que respeita às competências da Assembleia Municipal e das Câmara Municipais, a Lei n 75/2013 trouxe alterações que influenciaram o modelo da gestão autárquica. A análise do impacto da reforma nas competências da Assembleia Municipal, Câmara Municipal, Presidente da Câmara e Junta de Freguesia permitiu levantar questões em ambos os métodos de coleta de informações, a saber:

1. As vantagens, espectativas e enquadramento da reforma da Administração Local no quadro de competências das Freguesias e Câmaras Municipais.

2. O impacto da reforma da Administração Local no quadro de competências das Juntas de Freguesia, das Assembleias Municipais, das Câmaras Municipais, e dos Presidentes de Câmara. 
3. O reforço das competências da Assembleia Municipal, do Presidente da Câmara Municipal e dos Dirigentes autárquicos.

A análise de resultados associados às questões colocadas em ambas as metodologias utilizadas (Anexo I) sugere que as alterações introduzidas foram majoritariamente de forma e não de conteúdo. Esta afirmação é apoiada pelos seguintes fatos:

1. A Lei $n^{0} 75 / 2013$ não revoga por inteiro a Lei $n^{\circ}$ 169/99, alterada pela Lei $\mathrm{n}^{\circ}$ 5-A/2002, assim como o regime jurídico de funcionamento dos órgãos dos $\mathrm{Mu}$ nicípios e das Freguesias. Assim, pode-se afirmar que no novo regime jurídico das Autarquias não cobre todos os aspetos carecedores de regulação jurídica. No caso da Assembleia Municipal e Assembleia de Freguesia, não são revogados os artigos relativos a sua constituição, composição e primeira reunião;

2. Quanto à Assembleia de Freguesia, manteve-se o regime relativo à impossibilidade de eleição, convocação para o ato de instalação dos órgãos, instalação, primeira reunião, participação de membros da junta nas sessões e parte das competências;

3. No que respeita à Junta de Freguesia, não foram revogados os artigos relacionados ao regime de funções, bem como as funções a tempo inteiro e meio tempo, a repartição do regime de funções, e as substituições. No nível do plenário de cidadãos eleitores, mantém-se a composição do plenário, bem como o artigo referente à remissão;

4. Quanto à Assembleia Municipal, verifica-se a manutenção das normas relacionadas com as competências da Mesa, dos Grupos municipais e com a participação dos membros da Câmara da Assembleia Municipal.

5. Ao nível da Câmara Municipal, mantém-se as normas relativas à composição e aos vereadores a tempo inteiro 
e a meio tempo. Mantiveram-se algumas disposições comuns, como é o caso da duração e natureza do mandato, renúncia, suspensão e continuação do mandato, ausência inferior a 30 dias, preenchimento de vagas e formas de votação (alínea "d", do $n^{\circ} 1$, do art. $3^{\circ}$ da Lei ${ }^{\circ}$ 75/2013);

6. A reforma alarga as competências do Presidente da Câmara Municipal e do Presidente da Junta de Freguesia às respeitantes à Proteção Civil, que passam a ter reflexo nas competências próprias destes órgãos (Lei nº 27/2006). Por outro lado, a maioria dos entrevistados considera que, para além da Lei $n^{0}$ 75/2013 não promover qualquer reforma da Administração Local, a probabilidade de a mesma trazer vantagens ao nível das relações entre as Câmaras Municipais e as Juntas de Freguesia, é igualmente baixa (Gráfico 1).

Seguem, então, os resultados das respostas que nos foram dadas em resultado da aplicação dos questionários, tratadas nos gráficos seguintes.

Gráfico 1 - Pergunta: A reforma melhora articulação de funções entre a Junta de Freguesia e a Câmara Municipal?

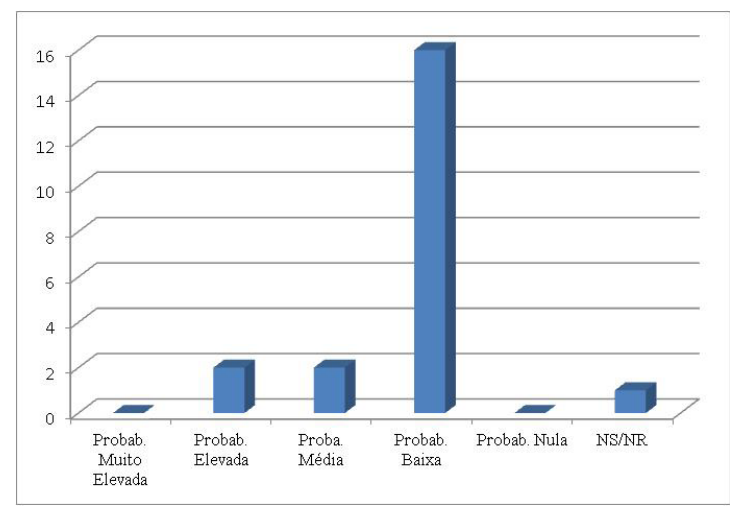

Fonte: Respostas ao questionário. Elaboração própria 
As respostas sugerem que a reforma não traz vantagens para as relações entre as Câmaras Municipais e as Juntas de Freguesia. $O$ processo de transferência de competências apresenta-se complexo e em muitos casos de difícil aplicação, já que nem todas as Câmaras Municipais terão capacidade para transferir os recursos humanos, patrimoniais e financeiros necessários para as Juntas de Freguesia, previsto no artigo 115 da Lei $n^{\circ}$ 75/2013. No âmbito das competências transferidas - $n^{\circ} 3$ do art. 16 -, os entrevistados consideram que nem todas as Juntas de Freguesia terão as condições para as aplicá-las de forma eficaz. Isso porque as competências das freguesias foram muito alargadas. As Juntas de Freguesia passam a poder emitir licenças para: venda ambulante de lotarias; arrumador de automóveis; atividades ruidosas de caráter temporário que respeitem a festas populares, romarias, feiras, arraiais e bailes.

As Juntas de Freguesia veem ainda reforçadas as competências junto das entidades locais de índole associativa e social, para: discutir e preparar com a Câmara Municipal contratos de delegação de competências e acordos de execução, nos termos previstos na presente lei; discutir e preparar com as organizações de moradores protocolos de delegação de tarefas administrativas que não envolvam o exercício de poderes de autoridade; discutir e preparar com instituições públicas, particulares e cooperativas que desenvolvam a sua atividade na circunscrição territorial da Freguesia protocolos de colaboração, designadamente quando os respetivos equipamentos sejam propriedade da Freguesia e se salvaguarde a sua utilização pela comunidade local; participar, em colaboração com instituições particulares de solidariedade social, em programas e iniciativas de ação social.

As Juntas de Freguesia têm consagrado na Lei o que já era uma prática decorrente das suas relações com as respetivas Câmaras Municipais, a saber: as competências para conservar e reparar a sinalização vertical não iluminada instalada nas vias municipais; manutenção e conservação de caminhos, arruamentos e pavimentos pedonais; construção dos equipamentos 
referidos quando eles se destinem a integrar o respetivo património: abrigos de passageiros; balneários, lavadouros e sanitários públicos; parques infantis públicos; chafarizes e fontanários e cemitérios.

A Lei $n^{\circ} 75 / 2013$ transfere, ainda, para as Juntas de Freguesia as seguintes competências das Câmaras Municipais: colocar e manter as placas toponímicas; gerir e manter espaços verdes; assegurar a limpeza das vias e espaços públicos; manter, reparar e substituir o mobiliário urbano instalado no espaço público; gerir e assegurar a manutenção de feiras e mercados; assegurar pequenas reparações nos estabelecimentos de educação pré-escolar e do primeiro ciclo do ensino básico e promover a manutenção dos seus espaços envolventes.

Para além dessas competências, o legislador definiu um conjunto de atribuições nas áreas do controle prévio, vistoria e fiscalização, que podem ser delegadas nas Juntas de Freguesia (n 2 do art. 13 da Lei n 75/2013). A Câmara Municipal perde autonomia de decisão para as Juntas de Freguesia, nomeadamente sobre a definição dos Acordos de Execução e da denominação de ruas e praças do seu território. Essa alteração pode levar a situações de negociação complexas, até mesmo com possível prejuízo da eficiência e eficácia (art. 16 e 18 da Lei $n^{\circ}$ 75/2013).

Por outro lado, a maioria dos autarcas que compõe a amostra considera que é baixa a probabilidade de as Assembleias e Câmaras Municipais reforçarem as suas competências (Gráficos 2 e 3). Há uma diminuição das competências da Câmara Municipal derivada da transferência de competências para as Juntas de Freguesia (art. 33 da Lei n 75/2013). A reforma não abrange alterações relativas à gestão estratégica dos órgãos, do território ou do orçamento municipal. Seguem, agora, representadas nos gráficos 2 e 3 , as respostas obtidas sobre a questão do reforço de competências das Assembleias e das Câmaras Municipais. 
Gráfico 2 - As competências das Assembleias Municipais foram reforçadas?

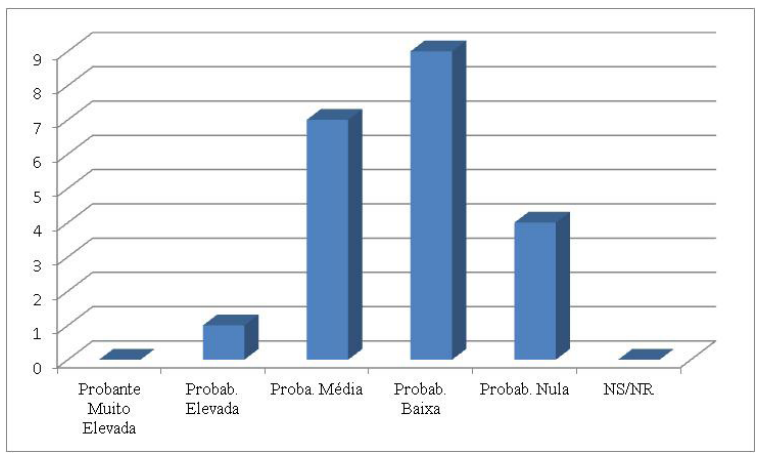

Fonte: Respostas ao questionário. Elaboração própria

Gráfico 3 - As competências das Câmaras Municipais foram reforçadas?

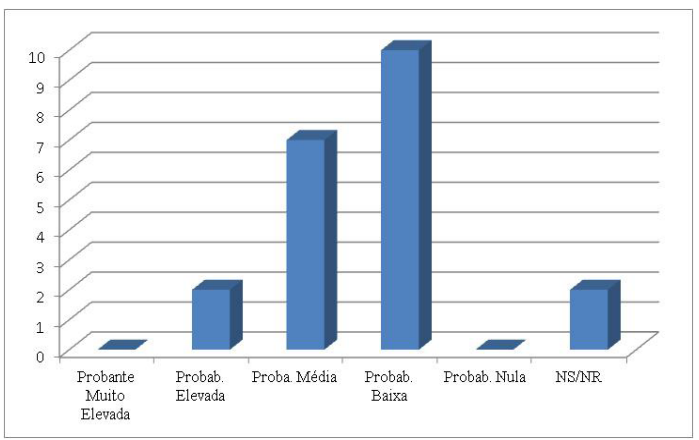

Fonte: Respostas ao questionário. Elaboração própria

As respostas dadas pelos entrevistados sugerem que as competências da Assembleia Municipal saem reforçadas, por conta de algumas razões em especial, a saber: são atribuídas competências para deliberar sobre formas de apoio às Freguesias (alínea "j", do $n^{\circ} 1$, do art. 2o da Lei $n^{\circ} 75 / 2013$ ); sendo a lei omissa sobre quem propõe a realização de referendos locais, a Assembleia Municipal é o único órgão do Município no qual há a referência a este instrumento de auscultação dos eleitores do respetivo território (alínea "e", do $n^{\circ} 2$, do artigo 24 da Lei 
$\left.n^{\circ} 75 / 2013\right)$; a competência para votar moções de censura e convocar o Secretariado das Comunidades Intermunicipais (alínea "b", do n 5, do art. 25 da Lei n 75/2013) foi incluída nas competências das Câmaras Municipais.

Em relação a essas competências, a maioria dos entrevistados considera que existe uma probabilidade média de a Assembleia Municipal ver as suas competências de apreciação e fiscalização reforçadas (Gráfico 4). Seguem, pois, as respostas dadas quanto às competências de fiscalização das Assembleias Municipais.

Gráfico 4 - As competências de apreciação e fiscalizaçãoda Assembleia Municipal foramreforçadas?

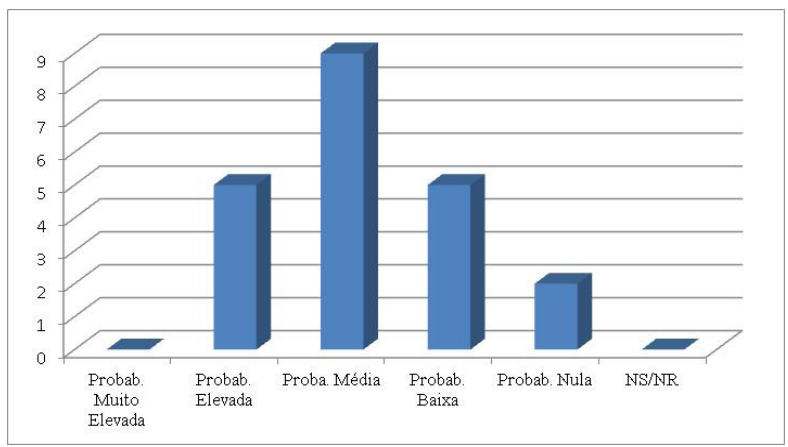

Fonte: Respostas ao questionário. Elaboração própria

A análise do Novo Regime Jurídico das Autarquias permite verificar que o Presidente da Câmara Municipal perde algumas competências: a Câmara Municipal deixa de as delegar (art. 34 da Lei $n^{\circ}$ 75/2013); algumas competências foram transferidas para a Câmara Municipal, apesar da possibilidade de delegação (alíneas "b" e "q" do art. 33 da Lei n 75/2013).

As respostas dos inquiridos sugerem que as alterações terão um impacto moderado na atividade estratégica da gestão autárquica, pois as competências da Câmara Municipal, que deixam de ser delegáveis no seu Presidente, estão associadas à fiscalização do cumprimento das deliberações da Assembleia 
Municipal, ao apoio e comparticipação da ação social escolar e atividades complementares no âmbito de projetos educativos e à realização de vistorias e execução da atividade fiscalizadora atribuída por lei (n 1, do art. 34 da Lei n 75/2013). Em relação às restantes competências do Presidente, que passaram a ser da Câmara Municipal, com capacidade de delegação do primeiro, destacamos a capacidade de executar obras por administração direta ou empreitada (art. 33 da Lei $n^{\circ}$ 75/2013). Em suma, o Presidente da Câmara Municipal perde competências associadas à gestão da despesa do Município.

Todavia, verifica-se também que algumas das competências do Presidente da Câmara Municipal deixaram de ser delegáveis e que outras passaram a poder ser delegadas aos dirigentes. É o caso das competências relacionadas com os poderes de:

a) Suspender ou encerrar antecipadamente as reuniões, quando circunstâncias excecionais o justifiquem (alínea "r", do n 1 , do art. 68 da Lei $n^{\circ}$ 169/99);

b) Representar a Câmara nas sessões da Assembleia Municipal ou, havendo justo impedimento, fazer-se representar por substituto legal (alínea " $\mathrm{t}$ ", do $n^{\circ} 1$, do art. 68 da Lei $n^{\circ}$ 169/99);

c) Responder aos pedidos de informação veiculados pela mesa da Assembleia Municipal (alínea "u", do n 1, do art. 68 da Lei n 169/99);

d) Promover a publicação das decisões ou deliberações previstas no art. 91 (alínea "v", do n 1 , do art. 68 da Lei n 169/99).

No que concerne às competências do Presidente da Câmara delegáveis aos dirigentes, consagrou-se na lei o que já se passava na estrutura local da Proteção Civil, ou seja, o Presidente da Câmara passa a poder delegar aos dirigentes a competência de dirigir o serviço municipal de proteção civil, para cumprimento dos planos de emergência, dos programas estabelecidos e para a 
coordenação das atividades a desenvolver, designadamente em operações de socorro e assistência na iminência ou ocorrência de acidente grave ou catástrofe (alínea "v", do n 1 , do art. 35 da Lei $\left.n^{\circ} 75 / 2013\right)$.

Os resultados dos questionários apontam no sentido de que a maioria dos inquiridos atribui uma probabilidade média ao impacto positivo que a reforma teve no quadro de competências do Presidente da Câmara (Gráfico 5). Seguem no gráfico as respostas sobre o reforço das competências dos Presidentes de Câmara.

Gráfico 5 - As competências do Presidente da Câmara foram reforçadas?

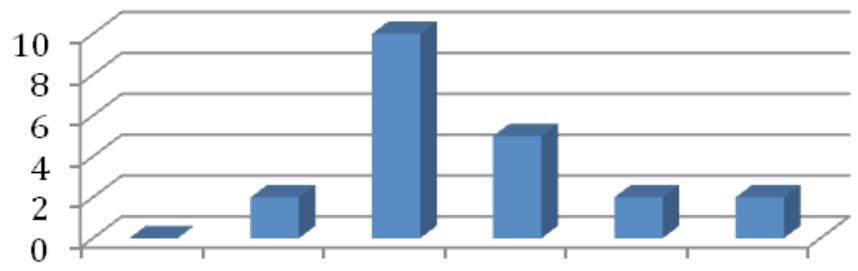

Probab. Probab. Proba. Probab. Probab. NS/NR

Muito Elevada Média Baixa Nula

Elevada

Fonte: Respostas ao questionário. Elaboração própria

Com efeito, este último gráfico demonstra que a maioria dos inquiridos considera média ou baixa a probabilidade de reforço das competências do Presidente da Câmara a partir das mudanças decorrentes da reforma normativa objeto desse estudo.

\section{CONCLUSÃO}

As conclusões da pesquisa sugerem que a reforma das Autarquias Locais de 2013, no que toca às competências dos órgãos autárquicos, tem pouca profundidade e demonstra alguma falta de estratégia da parte do Governo, principalmente pelos seguintes motivos: 
1. O Regime Jurídico das Autarquias Locais deveria concentrar todas as competências das Autarquias Locais em um único diploma legal, o que não e o caso (art. 3º da Lei $n^{\circ} 75 / 2013$ );

2. A maior parte das alterações está diretamente associada a questões de forma e organização do Poder Local e não propriamente sobre aspectos de conteúdo;

3. São transferidas competências de licenciamento das Câmaras Municipais para as Juntas de Freguesia $\left(n^{\circ}\right.$ 3, do art. 16 da Lei $n^{\circ} 75 / 2013$ ), o que pode provocar situações de conflito;

4. É mantida na Câmara Municipal a competência para exercer a atividade de comércio a retalho não sedentária, por feirantes e vendedores ambulantes, mas esta passou para a Direção Geral das Atividades Económicas (DGAE) (n 3, do art. $5^{\circ}$ da Lei $n^{\circ} 27 / 2013$; alínea "k", do n² 2, do art. 38 da Lei n 75/2013.

Os resultados sugerem que os autarcas inquiridos defenderam, na sua maioria, que as Autarquias devem ser alvo de reformas que contribuam para uma maior transparência, maior eficiência e eficácia da gestão autárquica. Com referência às hipóteses colocadas, os resultados sugerem o seguinte:

- Hipótese 1 - A reforma contribui para a articulação de funções entre a Junta de Freguesia e a Câmara Municipal - a opinião dos inquiridos é de que essa contribuição será pouco significativa ou nada significativa.

- Hipótese 2 - A reforma reforçou as competências da Assembleia Municipal, da Câmara Municipal e do Presidente da Câmara 4- a opinião dos inquiridos é de que, no que toca às Câmaras Municipais, esse reforço é pouco significativo, ao passo que para a Assembleia e a Câmara Municipal esse reforço é mais significativo ou mesmo significativo. 
- Hipótese 3 - A reforma reforça o papel das Assembleias Municipais como órgão fiscalizador da ação da Câmara Municipal e do Presidente - a opinião dos inquiridos é a de que esse reforço é fraco e / ou não se fará sentir.

As entrevistas realizadas sobre o funcionamento dos órgãos das autarquias, nomeadamente a Assembleia Municipal e a Câmara Municipal, permitem considerar a defesa de que a Câmara Municipal deva ter maior autonomia nas suas atuais competências, e que a Assembleia Municipal tenha uma maior capacidade de fiscalização e análise das atividades desenvolvidas pelo executivo camarário. Esse reforço deveria ser mais evidente na reforma.

A maioria dos entrevistados considera que os membros das Assembleias Municipais deveriam ter mais tempo e melhores meios para analisar a documentação enviada antes das sessões. Entre algumas sugestões, surge a de que as Assembleias Municipais deveriam ter a possibilidade de votar moções de censura à Câmara Municipal que tivessem consequências práticas para o Executivo. Porém, a consequência dessa ação não é consensual, pois se uns dos entrevistados consideram que isso poderia provocar a queda da Câmara Municipal e levar à convocação de eleições antecipadas, outros consideram que esta medida deveria ter uma função política, mas que não acarretasse a dissolução do respetivo órgão autárquico.

A maioria dos autarcas considera que a reforma do Regime Jurídico das Autarquias deveria ter maior alcance, ser mais profunda, indo ao encontro das primeiras propostas legislativas divulgadas pelo XIX Governo Constitucional, abandonadas no âmbito das negociações com os diferentes atores envolvidos.

A história tem mostrado que as competências das autarquias estão em permanente mudança, que nem sempre tem sido positiva para as autarquias. Quando tais mudanças coincidem com alterações de regime político ou com a melhoria 
da economia, os dados sugerem uma maior propensão para o desenvolvimento de regimes legais fomentadores da descentralização de competências do Poder Central para o Poder Local e de uma maior autonomia, como aconteceu, por exemplo, com os Códigos Administrativos de 1878 e de 1886, bem como mais recentemente com a atual Constituição portuguesa (CRP/1976).

O estudo da evolução das competências dos órgãos autárquicos deve acompanhar a dinâmica da mudança nessa área da vida coletiva e o constante debate de ideias que a acompanha, o que constitui fundamento mais do que suficiente para novos estudos sobre as reformas que virão futuramente.

\section{REFERÊNCIAS}

ALEXANDRINO, J. (2010). Direito das Autarquias Locais - Introdução, Principios e Regime Comum in Paulo Otero. Pedro Gonçalves (coord.). Tratado de Direito Administrativo Especial. Volume IV. Coimbra.

AMARAL, D. F. (1991, 2014, 3. ed.). Curso de Direito Administrativo. Volume I. Coimbra. Livraria Almedina.

ARAÚJJ, J. F. E. (2003). A Governação Local e os Novos Desafios. Comunicação apresentada no Fórum de Gestão e Administração Pública. Mirandela.

ASCENÇÃO, P. (2006). A reforma das organizações da Administração Pública: uma análise de um processo de mudança. Lisboa: 2006. Tese de Mestrado em Políticas de Desenvolvimento dos Recursos Humanos, Instituto Superior de Ciências do Trabalho e da Empresa. ISCTE.

BILHIM, J. (2004). A Governação nas Autarquias Locais. Porto. Sociedade Portuguesa de Inovação.

BRAVO, A.; SÁ, J. (2000). Autarquias locais: descentralização e melhor gestão. Lisboa: Verbo.

CATARINO, J. R. (2014, 2. ed.). Finanças Públicas e Direito Financeiro. Almedina, Coimbra.

CONDESSO, F. (1996). Lições de Direito e Gestão Autárquica. Lisboa. Preleções de Gestão Autárquica. ISCSP - UTL. Lisboa. 
. (2008). Governo Municipal - Administração Pública e Direito

Autárquico. Lisboa. Estudos ISCSP.

. (2012). As estruturas de governação em Portugal perante as assimetrias

de desenvolvimento territorial. Quê modelo seguir? Tese de Doutoramento.

Universidade da Extremadura.

COSTA, P. C. (2014). Nova Lei das Finanças Locais. Disponível em: http:// amal.pt/site/parameters/amal/files/File/Noticias/NLFL.pdf

FRANCO, A.; AMARAL, V. (2000). Representação do poder municipal e formação de impressões: Um estudo sobre a hipótese do presidencialismo municipal no Concelho de Cascais. Análise Psicológica [online]. vol. 18, n. 1. Lisboa. Instituto Superior de Psicologia Aplicada. Disponivel em: http://www. scielo.oces.mctes.pt/pdf/aps/v18n1/v18n1a07.pdf

MOZZICAFREDO, J.; GUERRA, I.; FERNANDES, M.; QUINTELA, J. (1988). O Grau Zero do Poder Local. Comunicação ao I I Congresso Português de Sociologia. Lisboa. Centro de Investigação e Estudos de Sociologia/ISCTE.

MAFRA, F.; SILVA, J. (2004). Planeamento e Gestão Territorial. Porto, Sociedade Portuguesa de Inovação.

Manual Técnico II: Métodos e Técnicas A Análise da Informação: Inquéritos Delphi Lisboa, (2009). O Observatório do QREN.

MoU - Memorando de Entendimento negociado entre o Governo Português, a Comissão Europeia, o Banco Central Europeu e o Fundo Monetário Internacional (MoU) (2011). Disponível em: http://www. portugal.gov.pt/media/371372/mou pt 20110517.pdf

NABAIS, J. (2007). A Autonomia Financeira das Autarquias Locais. Coimbra. Almedina.

OesteCim - Programa Territorial de Desenvolvimento do Oeste - Estratégia 2020. (2008). Disponível em: http://www.oestecim.pt/ uploads/

ProgramaTerritorialdeDesenvolvimentodoOeste.pdf

OlIVEIRA, A. (1993). Direito das Autarquias Locais. Coimbra. Coimbra Editora; (2009).

OLIVEIRA, C. (1996). História dos Municípios e do Poder Local. Lisboa. Círculo de Leitores;

PEREIRA, A.; ALMEIDA, M. (1985). Conhecer as autarquias locais. Porto: Porto Editora. 
PORTUGAL. Documento Verde da Reforma da Administração Local (2011).

Disponível em: http://www.portugal.gov.pt/media/132774/doc verde ref adm local.pdf

Programa Territorial de Desenvolvimento do Oeste (2008).

OesteCIM. Disponível em: http://www.oestecim.pt/ uploads/

ProgramaTerritorialdeDesenvolvimentodoOeste.pdf

Reforma do Estado. 2013. Disponível em: http://www.portugal.gov.pt/ media/1228115/20131030\%20guiao\%20reforma\%20estado.pdf

ROCHA, J. (2005). Regionalização no âmbito da Gestão Autárquica. Coimbra. Edições Almedina.

ROCHA, O. (2001). Gestão Pública e Modernização Administrativa. Oeiras: Instituto Nacional de Administração.

RUIVO, F. O Estado Labirintico: o poder relacional entre poderes local e central em Portugal. Porto, Edições Afrontamento, Lisboa.

SERRA, J. (1990). As Reformas da Administração Local de 1872 a 1910. Lisboa, in Análise Social. Revista do Instituto de Ciências Sociais da UL.

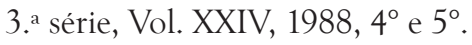

SOUSA, J. (2013). A Atual Reforma da Administração Local. Porto, Instituto de Investigação Jurídica da Universidade Lusófona do Porto.

XIX Governo Constitucional (2011). Documento Verde da Administração Local. Lisboa. Gabinete do Ministro-adjunto e dos Assuntos Parlamentares.

\section{LEGISLAÇÃO}

PORTUGAL. Decreto-lei n. 701-B/1976, de 29.09.1976 - Regula a organização do poder local.

PORTUGAL. Decreto-lei n. 77/1984, de 08.03.1984 - Regime de delimitação e da coordenação das atuações da administração central e local em matéria de investimentos públicos.

PORTUGAL. Decreto-lei n. 100/1984, de 29.03.1984 - Atribuições das autarquias locais e competência dos respectivos órgãos.

PORTUGAL. Decreto-lei n. 305/2009, de 23.10.2009 - Enquadramento jurídico da organização dos serviços das autarquias locais. 
PORTUGAL. Lei n. 79/1977, de 25.10.1977 - Atribuições das autarquias e competências dos respetivos órgãos.

PORTUGAL. Lei n. 1/1979, de 02.01.1979 - Lei de Finanças Locais.

PORTUGAL. Lei Constitucional n. 1/1997, de 20.09. 1997.

PORTUGAL. Lei n. 159/99, de 14.09.1999 - Quadro de transferência de atribuições e competências para as autarquias locais, bem como de delimitação da intervenção da Administração Central e da Administração local.

PORTUGAL. Lei n. 169/1999, de 18.09.1999 - Quadro De Competências E Regime Jurídico De Funcionamento Dos Órgãos Dos Municípios E Das Freguesias.

PORTUGAL. Lei n. 5-A/2002, de 01.01.2002 - Primeira alteração à Lei n. 169/1999, de 18.09.1999.

PORTUGAL. Lei n. 53-E/2006, de 29.12.2006 - Regime geral das taxas das autarquias locais.

PORTUGAL. Lei n. 45/2008, de 27.08.2008 - Regime jurídico do associativismo municipal.

PORTUGAL. Lei n. 22/2012, de 30.05.2012 - Reorganização administrativa territorial autárquica.

PORTUGAL. Lei n. 27/2013, de 12.04.2013 - Regime jurídico a que fica sujeita a atividade de comércio a retalho não sedentária exercida por feirantes e vendedores ambulantes.

PORTUGAL. Lei n. 73/2013, de 03.09.2013 - Estabelece o regime financeiro das autarquias locais e das entidades intermunicipais.

PORTUGAL. Lei n. 75/2013, de 12.09.2013 - Novo Regime Jurídico das Autarquias locais, aprova o estatuto das entidades intermunicipais, estabelece o regime jurídico da transferência de competências do Estado para as autarquias locais e para as entidades intermunicipais e aprova o regime jurídico do associativismo autárquico.

PORTUGAL. Resolução da Assembleia da República 28/1990, de 23.10. 1990 - Aprovação, para a ratificação, da Carta Europeia da Autonomia Local. 


\section{Anexo I \\ QUESTIONÁRIO}

Pedimos a colaboração de V. Exa. no preenchimento deste questionário, que se enquadra no âmbito do projeto de investigação intitulado "O Impacto da Reforma da Administração Local ao Nivel do Quadro de Competências da Assembleia e Câmaras Municipais". Este trabalho acadêmico, totalmente apartidário, pretende conhecer melhor o impacto da reforma do Poder Local de 2012.

\section{PARTE I - PROSPETIVA 1.REFORMA ADMINISTRATIVA}

\begin{tabular}{|c|c|c|c|c|c|c|}
\hline--- & $\begin{array}{c}\text { Probab. } \\
\text { Muito } \\
\text { Elevada }\end{array}$ & $\begin{array}{l}\text { Probab. } \\
\text { Elevada }\end{array}$ & $\begin{array}{l}\text { Proba. } \\
\text { Média }\end{array}$ & $\begin{array}{c}\text { Probab. } \\
\text { Baixa }\end{array}$ & $\begin{array}{c}\text { Probab, } \\
\text { Nula }\end{array}$ & $\begin{array}{l}\text { NS/ } \\
\text { NR }\end{array}$ \\
\hline $\begin{array}{l}\text { 1.1. Considera que a } \\
\text { reforma do Regime } \\
\text { Jurídico das Autar- } \\
\text { quias Locais e o Es- } \\
\text { tatuto das Entidades } \\
\text { Intermunicipais vai } \\
\text { ao encontro das } \\
\text { necessidades da Ad- } \\
\text { ministração Local? }\end{array}$ & & & & & & \\
\hline $\begin{array}{l}\text { 1.1.2.A reforma } \\
\text { propicia vantagens a } \\
\text { longo prazo? }\end{array}$ & & & & & & \\
\hline $\begin{array}{l}\text { 1.1.3. Concorda } \\
\text { com a proposta de } \\
\text { suspender o processo } \\
\text { de alteração da Lei } \\
\text { Eleitoral dos Órgãos } \\
\text { das Autarquias } \\
\text { Locais? }\end{array}$ & & & & & & \\
\hline $\begin{array}{l}\text { 1.1.4.A reforma per- } \\
\text { mitirá uma melhor } \\
\text { articulação de fun- } \\
\text { ções entre a Junta de } \\
\text { Freguesia e a Câmara } \\
\text { Municipal? }\end{array}$ & & & & & & \\
\hline
\end{tabular}




\section{COMPETÊNCIAS DOS ÓRGÃOS AUTÁRQUICOS}

\begin{tabular}{|c|c|c|c|c|c|c|}
\hline - & $\begin{array}{c}\text { Probab. } \\
\text { Muito } \\
\text { Elevada }\end{array}$ & $\begin{array}{l}\text { Probab. } \\
\text { Elevada }\end{array}$ & $\begin{array}{l}\text { Proba. } \\
\text { Média }\end{array}$ & $\begin{array}{r}\text { Probab. } \\
\text { Baixa }\end{array}$ & $\begin{array}{c}\text { Probab, } \\
\text { Nula }\end{array}$ & $\begin{array}{l}\mathrm{NS} / \\
\mathrm{NR}\end{array}$ \\
\hline $\begin{array}{l}\text { 1.2. As competências } \\
\text { das Juntas de Freguesia } \\
\text { serão reforçadas? }\end{array}$ & & & & & & \\
\hline $\begin{array}{l}\text { 1.3. As competências } \\
\text { das Câmaras Munici- } \\
\text { pais serão reforçadas? }\end{array}$ & & & & & & \\
\hline $\begin{array}{l}\text { 1.3.As competências } \\
\text { das Assembleias Munic- } \\
\text { ipais serão reforçadas? }\end{array}$ & & & & & & \\
\hline $\begin{array}{l}\text { 1.4. As competências } \\
\text { dos Presidentes de Câ- } \\
\text { mara serão reforçadas? }\end{array}$ & & & & & & \\
\hline $\begin{array}{l}\text { 1.5. As competên- } \\
\text { cias de apreciação e } \\
\text { fiscalização da Assem- } \\
\text { bleia Municipal serão } \\
\text { reforcadas? }\end{array}$ & & & & & & \\
\hline $\begin{array}{l}\text { 1.6. As competências } \\
\text { do Presidente da Câ- } \\
\text { mara serão reforçadas? }\end{array}$ & & & & & & \\
\hline $\begin{array}{l}\text { 1.7. As competências } \\
\text { dos Dirigentes serão } \\
\text { reforçadas? }\end{array}$ & & & & & & \\
\hline
\end{tabular}

\section{GUIÃO DE ENTREVISTA \\ Questão Exploratória}

1) Qual a sua opinião sobre a reforma da Administração Local promovida pelo XIX Governo Constitucional?

Caracterização da Reforma Administrativa

2) Em que medida esta reforma da Administração Local é condicionada pela crise económica e social?

3) Que vantagens poderão advir para as autarquias locais da aplicação da Lei n. ${ }^{\circ}$ 75/2013, que aprova o Regime Jurídico 
das Autarquias Locais e o Estatuto das Entidades Intermunicipais?

\section{As competências das Autarquias}

4) A reforma as autarquias locais, nomeadamente quanto aos Municípios e Freguesias, reforçará asrespetivas competências?

5) Considera que as alterações preconizadas por esta proposta de Lei levarão a perda de competências por parte das autarquias locais?Que tipo de perda?

\section{As competências dos Órgãos Autárquicos}

6) Concorda que a Assembleia Municipal deva ver as suas competências reforçadas?

a. Se sim, em que áreas?

7) Como veria uma potencial perda de competências do Presidente da Câmara em prol da Assembleia Municipal?

8) Qual a sua opinião sobre a possibilidade de os Dirigentes autárquicos poderem ver reforçadas as suas competências ao nível da Proteção Civil?

As competências das Comunidades Intermunicipais

9) Como avalia a transferência de competências das Câmara Municipais para as Comunidades Intermunicipais?

10) Na sua opinião, que impacto tem o chumbo do Tribunal de Constitucional na reforma preconizada por este novo Regime Jurídico das Autarquias Locais?

Artigo recebido em 29/07/2015

Artigo aprovado em 28/08/2015 